\title{
Novos desafios para a ideia de transparência pública ${ }^{1}$
}

Wilson Gomes, Paula Karini Dias Ferreira Amorim e Maria Paula Almada

\section{Resumo}

A pesquisa em transparência tem sido revigorado objeto de estudo das mais diversas áreas acadêmicas.

0 debate público sobre transparência vê-se

complicado por um conjunto de outros conceitos e verbetes (como publicidade e accountability) que com ele concorrem e a ele se sobrepõem, ganham novas ênfases. Este trabalho de cunho teórico tem o objetivo de ordenar a pluralidade de termos e conceitos mediante os quais a transparência pública é referida na literatura especializada; definir e pormenorizar a transparência pública e suas dinâmicas nas práticas e condutas de governos e instituições; sugerir o lugar dos recursos e ambientes da comunicação digital no futuro do debate sobre transparência pública.

\section{Palavras-Chave}

Democracia. Transparência Pública. Publicidade.

\section{Wilson Gomes}

Doutor em Filosofia pela Universitas a Scte. Thomae - Roma, Itália. Professor Titular da Faculdade de Comunicação da Universidade Federal da Bahia. Pesquisador e orientador no Programa de Pós-Graduação em Comunicação e Cultura Contemporâneas da Universidade Federal da Bahia (Salvador, Bahia, Brasil). E-mail: wilsonsg@terra.com.br

\section{Paula Karini Dias Ferreira Amorim}

Doutora em Comunicação e Cultura Contemporâneas pela Universidade Federal da Bahia. Professora do Instituto Federal de Educação, Ciência e Tecnologia do Tocantins - campus Palmas. Pesquisadora do CEADD - Centro de Estudos Avançados em Democracia Digital da Universidade Federal da Bahia (Salvador, Bahia, Brasil). E-mail: paula.karini@gmail.com

\section{Maria Paula Almada}

Doutora em Comunicação e Cultura Contemporâneas pela Universidade Federal da Bahia (Salvador, Bahia, Brasil). Pesquisadora de PósDoutorado (CAPES) do Instituto Nacional de Ciência e Tecnologia em Democracia Digital (INCT-DD). Universidade Federal da Bahia (Salvador, Bahia, Brasil). E-mail: mariapaula.almada@gmail.com

\section{A ideia de transparência pública}

Transparência é, naturalmente, uma metáfora antes de ser um conceito. Deve-se notar, antes de tudo, que é uma palavra recente, não reconhecida no latim clássico. É proveniente do adjetivo latino transparens-entis (composto pelo prefixo lat. trans - "trans" - e pelo verbo pareo "aparecer"), que surge apenas no latim medieval. No latim clássico, usava-se, para se referir à mesma coisa, outros adjetivos como perlucens, translucidus, perlucidus ou splendidus, que querem dizer "nítido" ou "límpido", aplicados, por exemplo, à água e ao ar. Quando começa a ser empregado, "transparente" serve para designar um corpo que deixa ver, de maneira mais ou menos clara, outros objetos que, do ponto de vista do observador, estão atrás, além dele.

Note-se desde já que transparente não se diz do corpo que exibe integralmente ao olhar, mas do corpo que não impede que o olhar passe através dele e vislumbre outros corpos que, caso fosse opaco, esconderia. A condição, digamos, natural dos corpos é a opacidade: corpos normalmente 
impedem que um observador que lhes esteja diante possa ver os outros corpos que se situam atrás dele. A exceção são os corpos transparentes, que não vedam a passagem do olhar, embora, e isso é importante, funcionem como filtros. Permitem que se veja através dele, mas essa visão, naturalmente, é limitada. 0 corpo transparente é diáfano, isto, é, deixa passar a luz, mas ainda assim é um corpo. 0 corpo que é o termo do olhar, literalmente, não é transparente, mas geralmente opaco. Por outro lado, transparente não é, de algum modo, o corpo que se vê, mas o corpo através do qual se pode ver outro corpo.

Transformando a palavra em conceito, deparamonos com uma decisão inicial: destaca-se, dos transparentes, 0 fato de que eles impedem uma visão integral do que lhes está por trás ou o fato de que permitem que se veja através deles? Claro que ambas as dimensões fazem parte do conceito, mas nos parece que 0 contraste entre "transparente" e "opaco" marque claramente que o que está realmente em questão é o trans + aparecer, é 0 fato de poder mostrar o que está por trás, do outro lado, mesmo sem que ele próprio tenha que desaparecer. Chegando ao campo das aplicações contemporâneas, uma instituição transparente não é, tecnicamente, simplesmente uma em que tudo está escancarado, acessível, disponível. Transparente, como o contrário de opaco, significa que uma instituição desta natureza é aquela em que não se veda 0 olhar, não há acessos blindados ou governos invisíveis, arcanos e mistérios, razões que não podem ser compartilhadas (as velhas Razões de Estado).

Na história da teoria política, contudo, parecenos que 0 conceito de transparência, embora muito valorizado em nossos dias, foi precedido, em tempo e valor, pela noção de "publicidade". É este, e não aquele, o conceito mormente empregado pelos clássicos do pensamento liberal para designar aquela característica normativa do Estado liberal-democrático que se colocava em perspectiva (I. Kant) ou se institucionalizava (J. Bentham). Kant foi o primeiro a usar a ideia de Publizität para conferir uma plataforma moral para 0 direito e a política (KANT, 1795), princípio nunca abandonado pela teoria política de base kantiana (HABERMAS, 1992; RAWLS, 1971). Por outros caminhos e com outros propósitos, a teoria política do utilitarismo adotou a mesma publicity (BENTHAM, 1839) com fundamento moral para a vida pública.

\section{0 argumento em favor da publicidade}


- normas, políticas e decisões cuja efetividade dependa do segredo diante daqueles que são por elas afetados não podem ser moralmente satisfatórias - é um teste de suficiência moral. 0 que quer que seja reprovado neste princípio fica destituído de base moral.

Jeremy Bentham adota a publicidade como forma de evitar 0 abuso do poder político por parte das autoridades. Em última instância, como forma de garantir que o poder político no Estado não seja desviado para beneficiar os agentes públicos em prejuízo do interesse geral. Como forma, em suma, de manter realmente pública a res publica. Sem querer simplificar demais, mas para fins de didatismo, diríamos que, no normativismo kantiano, a publicidade é um experimento conceitual e moral que funciona como teste normativo da consistência moral de uma norma ou política, enquanto no utilitarismo benthamiano, avesso ao imperativo categórico, a publicidade é basicamente um constrangimento: peias e controles morais que se usam para evitar que os apetites de uns sejam satisfeitos em prejuízo do interesse público.

Mas por que quem exerce o poder em nome de outros precisa de sistema de constrangimentos?

Não é meramente uma questão de caráter, de forma que a autoridade pública fosse necessariamente menos virtuosa que os cidadãos. Trata-se simplesmente do fato de que quem detém uma grande autoridade estará sempre submetido à tentação de abusar dela, isto é, de usá-la em benefício próprio. Uma autoridade pública, por definição, ocupa-se dos negócios públicos, portanto, dos outros, cuja satisfação é claramente menos vantajosa do que a saciedade dos próprios interesses. Ademais, tem à sua disposição os meios de satisfazer-se, às expensas do público. Quem é que, em sã consciência, se interpõe entre os seus apetites e a satisfação deles? 0s kantianos diriam que é a lei moral que cada consciência comporta em si, o imperativo categórico que nos diz para agir como se a nossa ação devesse ser o parâmetro da ação de todos. Os utilitaristas nos dirão que o que nos faz resistir a colocar nossos interesses em primeiro lugar é 0 temor da opinião pública e do seu julgamento, o desejo de preservação da nossa imagem e reputação, o que só de fato se concretiza se as nossas ações se derem à vista de todos (GUTMANN; THOMPSON, 1996). A publicidade é, antes de tudo, uma poderosa sanção social, um constrangimento consistente para que os indivíduos se comportem de maneira virtuosa principalmente em situações em que estejam sob forte tentação.

Além disso, a publicidade não apenas constrange as autoridades públicas a fazerem o que deles é esperado por todos, mas é também valiosa "por ser uma amiga da accountability", bem como por encorajar "os cidadãos a deliberar sobre políticas públicas" e por possibilitar "que autoridades aprendam sobre a e da opinião pública" (GUTMANN; THOMPSON, 1996, p. 97). Como se vê, a publicidade finda por se constituir num sistema de interface entre os que tomam as decisões 
políticas ou tomam decisões e implementam políticas públicas, no interior do Estado, e os cidadãos em geral. Assim, em primeiro lugar, ela age em favor da responsabilização das autoridades (no seu duplo e completar sentido, de obrigar a autoridade a responder, legal e administrativamente, por seus atos e de obrigála a se explicar por eles): governos invisíveis são, literalmente, governos irresponsáveis. A segunda dimensão da publicidade tem a ver com a valorização da opinião e da vontade dos cidadãos, neste caso dotados de insumos (informações e conhecimento) para proceder ao escrutínio argumentativo dos fatos e feitos da autoridade pública "em seu nome". A terceira dimensão, a esta associada, prende-se ao fato de que a autoridade pública tem, nas arenas da discussão gerada e sustentada pela visibilidade dos atos dos agentes públicos, meios e oportunidades para considerar o juízo público sobre temas e fatos em questão.

Tanto em Kant como em Bentham, a publicidade é um instrumento para 0 alinhamento entre 0 comportamento do indivíduo e as normas morais gerais voltadas para o benefício de todos. Mas enquanto Kant concentra a sua atenção no que pode justificar o valor para todos de um determinado comportamento ( 0 fato de ele se apoiar em razões públicas ou razões que todos os afetados por uma ação poderiam aceitar como válidas), Bentham está concentrado no que pode forçar o comportamento individual a ficar nos limites do interesse público (a publicidade como condição na qual a ação se realizará). Neste sentido, a publicidade como teste intelectual e moral parece uma garantia menos firme para 0 desenho de instituições eficazes para evitar que autoridades sacrifiquem o interesse público em benefício das suas próprias conveniências.

Da máxima kantiana da publicidade decorre, de fato, uma ética da argumentação pública e regras normativas sobre a legitimidade da esfera de discussão pública. 0 que não é pouco para uma teoria democrática coerente, mas certamente não é muito em termos de formação de instituições voltadas para se garantir que ações e decisões de indivíduos e grupos que desfrutam do poder público não se desgarrem do interesse geral da comunidade política. Eis a razão por que a noção de e a condição de publicidade (e não as razões públicas) se consolidaram como parâmetros da qualidade democrática de comportamentos e decisões de agentes públicos na democracia liberal.

A pensar bem, o conceito de publicidade vem dar um novo suporte à clássica aspiração liberal de que governos legítimos são apenas os baseados no consentimento dos governados. Já 0 velho John Locke insistia que era a presença do povo, na forma de legisladores eleitos supervisionando a coroa, "o melhor guardião da liberdade, vez que requer que o governo se torne obrigado a responder perante os governados". Pois bem, não é apenas de liberdade que se trata: a premissa de que a coisa que as pessoas mais 
desejam é a liberdade, e que, por conseguinte, resistiriam a qualquer esforço do Estado para dela se assenhorar, tem o seu duplo simétrico no pressuposto de que as pessoas não desejam ser governadas por potências invisíveis, desobrigadas de prestar conta dos seus feitos ou de responder pelos seus atos, servindo-se para isso do segredo ou da reserva. À supervisão do governo por representantes eleitos corresponde, de algum modo, a supervisão do Estado por todos os cidadãos, ambos como formas de torná-lo accountable perante os governados.

\section{De volta à transparência}

A razão pela qual "transparência" tornouse a expressão preferida para dar conta da normatização e institucionalização do princípio democrático da "publicidade" nos escapa, mas 0 fato é que, hoje, essa é a expressão consagrada para se falar da condição de exercício da autoridade pública sob o controle cognitivo alargado dos cidadãos e de instituições externas ao Estado. No estado atual da compreensão do conceito, transparência é uma condição e um princípio; antes, uma condição que responde a um princípio moral e democrático. Uma condição e um princípio a que se obriga tudo aquilo em que consiste a atuação em nome do povo (de decisões administrativas ao processo legislativo, do gasto às políticas públicas, das sentenças às regulamentações de leis, da decisão policial ao comportamento do agente público), em maior ou menor grau, com maior ou menor exigência, a depender do Estado e do nível de comprometimento das suas instituições e da sua cultura política.

Dito da maneira mais simples possível, há transparência quando há controle cognitivo externo de um ato, ou do que dele resulta, para além do agente que 0 praticou. Por controle cognitivo entende-se uma adequada compreensão de um comportamento ou do seu resultado por meio de volumes apropriados de dados, informações e conhecimento. Há transparência quando sujeitos independentes do agente ou dos agentes públicos que praticaram determinada ação têm acesso à informação necessária para saberem, pelo menos, que ato foi praticado, por quem e com qual escopo.

0 nível de transparência alcançado sempre tem a ver com, pelo menos, três dimensões: (a) os assuntos e âmbitos sobre os quais se podem produzir informação pública; (b) a extensão e a qualidade da informação disponível, e (c) 0 montante de pessoas e de classes de pessoas a quem é permitido acesso a essa informação. Quanto mais extensa e clara a informação disponível, quanto maior o número de pessoas a quem essa informação for disponível, mais transparente será o Estado. Diferentes administrações públicas, legislaturas ou configurações do Judiciário podem adotar diferentes políticas de transparência pública, por exemplo, aumentando ou diminuindo 0 número dos objetos submetidos ao regime de 
transparência, a quantidade da informação disponível e o número de olhos que podem acompanhar decisões e processos in fieri ou $a$ posteriori. Ou essas variações podem não ser deixadas simplesmente às ênfases específicas das autoridades no comando de algum Poder do Estado e se tornar política da nação, materializadas coercitivamente em estruturas legais, políticas e institucionais.

0 compromisso com a publicidade, materializado em instituições e normas, vem crescentemente tornando-se uma marca distintiva de qualidade democrática dos Estados contemporâneos. Sem mencionar as clássicas emendas constitucionais sobre a liberdade de expressão e de imprensa, leis de acesso a documentos, registros e atas (ou Sunshine Laws), marcos legais sobre a liberdade de informação e, por último, as iniciativas e projetos internacionais de "governo aberto" (OPEN GOVERNMENT DIRECTIVE, 2009), com todas as consequências implicadas, são exemplos claros da onda mundial de adesão ao compromisso com a transparência pública. Por fim, a tendência para maior transparência não se limita às decisões no Estado, mas ultimamente se estende para incluir instituições como bancos centrais e até mesmo empresas privadas, inclusive as estrangeiras operando no território de um país (FINEL; LORD, 1999).

A tendência contemporânea para a transparência tem incluído o reforço dos mecanismos que levam a mais abertura do Estado, em que há valorização do jornalismo e de outros recursos e atividades profissionais voltadas para a produção e distribuição de informação, o crescimento de audiências públicas e de iniciativas de dados abertos e 0 incremento considerável de organizações independentes voltadas para a distribuição de informação sobre governos, sistemas políticos, sistemas financeiros etc.

Embora todas as democracias liberais (e até instituições de Estados não democráticos e empresas privadas) tenham assimilado 0 princípio de publicidade, e até se comprometido com ele de algum modo, o nível de transparência adotado é sempre dependente de políticas de transparência ou de estruturas legais, políticas e institucionais que estabelecem $o$ que pode ser visto, quando e como pode ser visto e por quem (por quantos) pode ser visto. Afinal, segredo, reserva e privacidade continuam valores ativos, mesmo em regimes estritamente liberais. Demais disso, é evidente que atores sociais fortes tendem a se eximir das obrigações e constrangimentos que os regimes de publicidade comportam, e há uma perene tensão política entre a publicidade que se deseja e a publicidade que se consegue. 0 fato de nunca se ter falado tanto de transparência como agora não implica que a transparência não enfrente desafios cada vez maiores.

Além disso, há a questão do "momento" da transparência. Aos deliberacionistas, como James Bohman (BOHMAN, 1996, 1999), Amy Gutmann e Dennis Thompson (GUTMANN; THOMPSON, 
1996), por exemplo, a ideia que lhes parece mais agradar é a da publicidade como condição da discussão alargada dos cidadãos na esfera pública. Neste sentido, a ideia de uma publicidade ou transparência que se aplique a posteriori, isto é, sobre atos, normas e decisões já tomadas, parece como que desprovida de certas qualidades essenciais. A transparência que estamos aqui qualificando como a posteriori não apenas não evita 0 dano já praticado pela autoridade que tomou a decisão errada ou injusta nem repara o fato de que cidadãos inocentes já possam ter sofrido por ela, mas, sobretudo, não garante 0 que, para os deliberacionistas, a transparência, ao fim e ao cabo, deveria assegurar - que os cidadãos decidam, juntos, que tipo de políticas eles desejam. Desta forma, o melhor momento para a efetividade de um regime de transparência é quando práticas e políticas estão em processo, estão acontecendo ${ }^{2}$.

Os deliberacionistas apresentam quatro bons argumentos para defender a transparência in fieri (ou apresentação pública antecipada das justificativas de uma política) versus uma transparência a posteriori (através de relatórios e da prestação pública de contas) (GUTMANN; THOMPSON, 1996 p. 101). São elas: 1) 0 consenso antecipado a uma política pública é a forma eminente de garantir-lhe legitimidade e de tornar possível a cooperação dos outros cidadãos; 2)
Os cidadãos, partícipes da decisão que lhes é apresentada previamente, têm confirmada a sua convicção sobre as regras da boa conduta republicana; 3) Razões públicas antecipadas supõem e firmam o respeito recíproco entre as partes da sociedade, mesmo no que tange a desacordos morais permanentes, e ajudam a construir canais de recíproco esclarecimento; 4) Autoridades e grupos da sociedade podem mudar a sua própria opinião, diante de razões públicas antecipadas para uma política.

Por mais que se reconheça 0 valor de razões públicas apresentadas previamente à tomada da decisão política ou à implementação de uma política pública, seria pouco razoável imaginar que grandes decisões legislativas e administrativas e programas e normas de ações que compõem políticas públicas são os únicos objetos que seria prudente imaginar submetidos a um regime rigoroso de transparência pública. Não apenas porque há decisões sobre ações que simplesmente não podem ser submetidas a um processo de antecipação e discussão de razões (pense-se no conjunto contínuo de decisões administrativas tomadas diariamente no Estado), não somente porque há decisões que, embora tenham publicadas as suas justificativa, não estão submetidas à deliberação pública (decisões judiciais, algumas decisões legislativas), mas sobretudo porque não haveria ganhos para a 
democracia em deixar de solicitar transparência a posteriori de tudo o que diga respeito às decisões tomadas, por quem de direito, no que se refere aos negócios públicos. Neste sentido, relatórios, balancetes, atas, depoimentos e outras respostas que órgãos responsivos do Estado têm que apresentar sob regime de transparência, têm tanto valor para o reforço do poder relativo dos cidadãos perante a autoridade pública quanto a possibilidade de discutir os assuntos públicos quando as decisões políticas ainda não foram tomadas. Afinal, government based on the consent of the governed e accountable government são, por assim, dizer, duas faces da mesma moeda.

Se concebemos que, para uma política pública ou uma lei, não é suficiente que sejam apenas relatadas e justificadas a posteriori, para muitos outros atos do governo, da burocracia da administração pública, do legislativo ou do judiciário é suficiente que a ação e 0 agente público que a praticou sejam obrigados a regimes de transparência e submetidos às sanções que deles decorrem. Dito de outro modo, entendemos que políticas públicas, principalmente as que envolvem grandes projetos e programas, precisem ser discutidas em um processo de deliberação pública, antes de serem implementadas. Mas entendemos, também, que as autoridades eleitas, os gestores nomeados e os funcionários envolvidos tenham que dar explicações públicas sobre suas decisões, ações e práticas sempre que forem solicitados a tanto, mesmo que seja depois da ação praticada. A avaliação pública, como parte do processo de produção de boas decisões políticas, parece-nos inquestionável na maioria dos casos de produção de decisão política, mas a revisão pública a posteriori, por meio da qual outros órgãos do Estado e os próprios cidadãos podem realizar uma avaliação das decisões tomadas, com possibilidade, inclusive de desaprovação das políticas e das decisões, além da responsabilização dos envolvidos, é fundamental para a democracia.

\section{Caracterizando a transparência}

Se sairmos do território da ideia de transparência na direção da caracterização dos tipos e modelos de transparência adotados, entretanto, teremos que começar a fazer distinções e a estabelecer escalas de intensidade. E há aqui várias clivagens importantes para que se possa de fato caracterizar o regime de transparência existente em um determinado Estado, governo, instituição ou organização.

Quem pode ver? Se começarmos com a questão transparente para quem?, por exemplo, teremos que decidir sobre as categorias de audiências ou públicos cujo acesso é autorizado, ou requerido, às informações sobre as ações de autoridades e funcionários públicos, em particular, e sobre quaisquer dados reunidos e organizados pelo Estado, em geral. Neste sentido, a expressão "transparência pública" pode ser consideravelmente ambígua, uma vez que há 
transparência pública quando a informação está disponível principalmente para os órgãos e instituições de controle horizontal no interior do próprio Estado ou quando o destinatário primário da informação é 0 cidadão em geral. Isso acontece porque, geralmente, 0 adjetivo "público" refere-se à fonte da informação (o Estado, no todo ou em suas partes) e não ao destinatário dela.

De qualquer forma, como sabemos, há diferentes esferas de destinatários, ou "públicos", da informação pública: órgãos de controle, o Poder Judiciário, o Poder Legislativo por meio de comissões específicas, por exemplo, governantes eleitos e titulares de pastas na administração pública, especialistas, membros de comitês nomeados pelo próprio governo, os cidadãos do país, qualquer pessoa. Os que têm acesso à informação, em diferentes formas, distribuemse de forma piramidal, vez que apenas alguns têm a prerrogativa de disporem de informações completas e contínuas sobre tudo (em geral, órgãos de controle, p. ex.) ${ }^{3}$. Além disso, há aqueles públicos para os quais essa informação é garantida por estruturas legais, posição política e institucional, e aqueles que dependem de políticas adotadas por titulares de governos, órgãos ou repartições. A tarefa de incluir o cidadão comum como o destinatário do máximo possível de informação qualificada, assegurando-lhe garantias legais e institucionais para tanto (portanto, livrando-o do arbítrio do poder discricionário do agente público) é tarefa a que hoje se impõem Estados nos quais a tendência à transparência é consistentemente levada a sério. Isso se justifica porque, como visto, a ideia de uma pirâmide de acesso demasiado restritiva, no que diz respeito ao conjunto dos cidadãos, parece incompatível, por princípio, com a ideia de um governo responsivo.

0 que pode ser visto? A segunda pergunta diz respeito ao objeto da transparência: o que a transparência deixa ver? Há, certamente, níveis variados de compromisso dos Estados com o princípio da publicidade e com a prática da transparência pública que produzem esferas mais ou menos intensas de transparência. No Brasil, o Judiciário, por exemplo, é um âmbito do Estado com notável poder de demandar transparência dos outros Poderes, mas um zeloso guardião da própria opacidade, temeroso de que a transparência possa tornar os seus agentes vulneráveis à opinião pública. A administração pública federal sofre maiores constrangimentos à transparência do que os Executivos estaduais e municipais, por exemplo. Mesmo na administração pública, há setores mais ou menos transparentes. Aqui também, o incremento do objeto da transparência pública, reduzindo ao mínimo necessário a opacidade do Estado, é uma tarefa 
importante para a construção de governos

responsivos, mas o movimento mais audacioso consiste em retirar a decisão sobre o que deve ser aberto do poder discricionário de gestores e funcionários e transferi-las para a norma legal.

No caso brasileiro, são notáveis alguns empreendimentos nesta direção. 0 primeiro é relacionado à contabilidade pública e corresponde ao que podemos chamar de "transparência fiscal". Refere-se às informações relativas às receitas (arrecadação) e às despesas (gastos) do governo, por determinação da Lei Complementar (LC) $\mathrm{n}^{0}$ 101/2000, que estabelece que a União, os Estados e os Municípios são obrigados a dar ampla divulgação, inclusive em meios eletrônicos de acesso público, a seus planos, orçamentos e leis de diretrizes orçamentárias, a suas prestações de contas e ao respectivo parecer prévio e, por fim, ao relatório resumido da execução orçamentária e do relatório de gestão fiscal. A Lei impõe às administrações públicas a obrigação de apresentar a origem dos fundos e a sua destinação no contexto da ação pública, por meio de documentos financeiros oficiais das autoridades e de mecanismos de verificação externa de relatórios.

0 segundo trata da obrigatoriedade de publicar em tempo real (até o primeiro dia útil subsequente à data de registro contábil no sistema de controle) as informações relativas à execução orçamentária e financeira de receitas e despesas em meio digital de acesso público. Estamos falando LC $\mathrm{n}^{0}$ 131/2009, que alterou 0 artigo 48 da LC 101/2000.
0 terceiro tem por objeto medidas mais gerais de transparência governamental ou administrativa, e refere-se às informações relativas ao modo de funcionamento do governo e tem seu amparo legal na Lei $n^{0}$ 12.527/2011. A transparência governamental ou administrativa representa as formas de organização e processo para permitir a reversibilidade completa da troca de informações entre cidadãos e governo. 0 objeto aqui é o acesso às informações que estão sob o poder dos órgãos em relação aos cidadãos e à instituição governamental. Diz respeito a informações sobre a organização e o funcionamento do governo. Por exemplo, atribuições e responsabilidades da equipe diretiva ou informações explicativas sobre 0 processo de aprovação de leis. Em maio de 2012 foi publicado o Decreto ${ }^{0} 7.724$, que tem como finalidade definir os procedimentos que garantam 0 acesso à informação e a classificação de informações no âmbito do Poder Executivo Federal.

0 mais recente exercício de trazer para a esfera legal o imperativo da transparência foi a aprovação do Decreto no 8.777/2016, que instituiu a política de dados abertos do poder executivo federal. Essa iniciativa mostra-se como uma forte promessa de alargamento da publicidade e de novas possibilidades de uso e reuso da informação pública.
No conjunto, alcançamos certo nível de transparência pública, que, se não nos torna um 
exemplo de país governado por sunshine laws, ao menos nos afasta do padrão dos regimes opacos dominados pelo patrimonialismo e todas as suas consequências. Temos um bom nível de disclosure nos processos em que as decisões governamentais e estatais são tomadas, se bem que militares, governos e ministros podem suprimir ou dificultar 0 acesso a informações. Há um fluxo razoável de informação proveniente do governo informação relativamente precisa sobre reuniões governamentais, audiências e outros eventos e atividades oficiais estão publicamente disponíveis, mas relatórios e documentos críticos ao governo, nem tanto. Os partidos de oposição supervisionam o governo, embora haja tensão permanente entre informação solicitada e informação tornada disponível. A nossa imprensa é livre, bastante plural e consideravelmente influente no debate sobre políticas e ações de governo. E temos um alto grau de debate público alargado sobre políticas, decisões e ações do governo por meio de partidos bem mobilizados, grupos de interesse e por meio dos cidadãos em geral. Mas, embora tenhamos caminhado aceleradamente para a institucionalização e a legalização do acesso à informação, a transparência consistentemente esbarra em cotas iníquas de poder discricionário ainda em mãos dos gatekeepers do Estado.

Qual é a fonte da informação? Partimos neste artigo de um conceito de transparência que inclui necessariamente 0 controle cognitivo sobre as ações (e sobre 0 que delas resulta) praticadas por um determinado agente em um governo, instituição ou organização. Insistimos que há transparência apenas quando há informação sobre os atos que se praticam em volume e qualidade suficientes para que um "olhar externo" ("externo", evidentemente, à órbita dos agentes) possa formar uma adequada compreensão da ação praticada. A este ponto acreditamos ser claro que a informação que produz transparência não se destina simplesmente à mesma esfera que a produz: toda transparência é uma introdução de um regime de heteronomia numa esfera geralmente autônoma. A autonomia produz esprit de corps, autoindulgência, redes de complacência recíproca, compadrio etc., que só podem ser rompidos por meio do olhar heterônomo. Dada a premissa, a questão prática a este ponto é: quem produz, reúne e organiza as informações necessárias para que um olhar heterônomo se torne possível? Esta é a questão das fontes da informação usadas em regimes de transparência.

Quando há normas e bases legais para sanções, a resistência a abrir mão da autonomia em favor da transparência tende a ser vencida, ou os custos que a resistência paga são tão altos que ela tende a ser praticada apenas quando as recompensas cobrem os riscos. Quando há apenas diretivas baseadas em princípios gerais e recomendadas à boa vontade dos agentes, a autonomia fatalmente prevalece sobre a heteronomia, e os sistemas se fecham. Há, claro, outros fatores em jogo, como a cultura política (valores e significados compartilhados socialmente), qualidade das instituições de controles e do sistema de pesos 
e contrapesos que funcionam no Estado. E há, sobretudo, os sistemas peritos em produzir informações aptas ao controle cognitivo das instituições à revelia dos seus agentes, o que inclui desde outros setores do Estado com poder de investigação e inquérito, passando pelo jornalismo investigativo e chegando até as práticas de vazamento de documentos e dados confidenciais por parte de insiders que se rebelam contra o corporativismo ou fazem retaliações que se explicam por redes de alianças e inimizades.

Neste quadro, Tribunais de Contas, por exemplo, uma vez que há leis determinando que informações e quais informações lhes devem ser prestadas pelos agentes públicos, funcionam à base de dados cuja fonte são os próprios agentes que fiscalizam. 0 controle para garantir a contenção da autonomia das fontes (e a fidedignidade da informação prestada) é dado por prescrições legais, dentre as quais se incluem as penas aplicadas quando do descumprimento da norma. Outros órgãos (CPIs, Ministério Público) têm acesso irrestrito às informações públicas, mas não esperam das instâncias internas todos os dados de que necessitam, sendo necessário instaurar inquéritos e procedimentos de investigação. Neste caso, prevalece a irrupção heterônoma uma vez que não se pode esperar completo provimento de informação confiável de quem se suspeita.

Na mesma linha da busca ativa de informação se coloca o jornalismo investigativo e qualquer outro sistema de produção e difusão de informações sobre governos e organizações baseado em coleta de informação por meio de documentos, depoimentos e apuração. Embora possa se apoiar em cooperação de fontes e informantes de dentro das instituições, o jornalismo, e não os agentes, é quem produz as narrativas que dão sentido aos fatos e explicam antecedentes e consequentes. Diferentemente dos órgãos de accountability horizontal, o jornalismo não conta geralmente com a ajuda de leis que aumentem o "nível de acesso" dos jornalistas à informação ou que lhe conceda direitos de receber relatórios e balancetes produzidos por agentes dos próprios governos e organizações, devendo coletar e organizar a informação necessária para permitir ao público um olhar heterônomo sobre a conduta das instituições. No máximo, o jornalista pode entrar pelas mesmas portas e janelas que Sunshine Laws abrem para os cidadãos em geral, obviamente fazendo um melhor uso, em virtude da competência técnica dos ambientes profissionais do jornalismo, dos dados (geralmente brutos) obtidos do sistema.

Por essas mesmas portas e janelas é que podem entrar as organizações não governamentais especializadas em coletar dados abertos e em produzir interfaces e outputs inteligíveis para os cidadãos. Esses novos atores só puderam existir e se multiplicar quando dados abertos, governos abertos e leis de acesso apareceram como resposta típica às pressões, inclusive internacionais, por mais transparência pública. Cada um a seu modo, 
jornalismo e organizações não governamentais dedicadas à transparência pública são hoje dois sistemas importantes, externos e independentes dos Estados e das suas instituições, encarregados de jogar luz sobre o comportamento dos agentes públicos, especializados, portanto, em uma espécie de transparência que é heterônoma seja como posição institucional (fora do Estado) seja como fonte de informação.

No meio do caminho entre autonomia e heteronomia, estão formas muito recentes de cooperação entre instâncias do Estado - como governos e parlamentos, mas também ministérios e secretarias - e pessoas, membros ou não de organizações e coletivos externos ao Estado, dotadas de expertise no acesso e no tratamento de dados públicos digitais. A condição de possibilidade desta cooperação foi dada pela mais recente onda de transparência pública, materializada no chamado open government, um conjunto integrado de marcos legais, projetos e iniciativas, altamente incentivado por governos e organismos multilaterais, cujo fim é produzir instituições do Estado com a mais ampla escala de acessibilidade a dados e informações públicas (HARRISON et al., 2012; LINDERS; WILSON, 2011; LUNA-REYES, BERTOT; MELLOULI,
2014; MCDERMOTT, 2010; MEIJER; CURTIN; HILLEBRANDT, 2012; MESKELL, 2009). 0 governo aberto é a mais nova materialização do clássico princípio liberal da publicidade, ainda entendido como meio de produção de governos responsivos e baseados no consentimento dos governados, mas em um contexto de explosão e consolidação de dados e comunicações digitais. Instrumento fundamental do governo aberto e parte essencial da sua ancoragem em ambientes quase integralmente digitais são os chamados open data ou dados públicos abertos ${ }^{4}$ (SHADBOLT et al., 2012).

\section{Transparência Digital}

A e-transparência (ou eTransparência) é uma linha de pesquisa nova e promissora no âmbito dos estudos sobre publicidade pública e transparência (AMORIM, 2012; ALMADA 2017). Analogamente ao tema da eParticipação, cuja pesquisa é naturalmente bem mais consolidada, 0 prefixo "e-" indica apenas que 0 substantivo que se segue limita-se ou circunscreve-se ao universo dos dados e informações digitais (SAMPAIO, 2014). A transparência digital, basicamente, é aquela produzida que emprega recursos ou meios digitais (HEALD, 2006; MARGETTS, 2006; MEIJER, 2009).

Por trás da ideia de dados abertos está, antes de tudo, uma prescrição normativa, segundo a qual governos democráticos devem abrir os seus dados, isto é, devem abrir acesso praticamente aos dados que o Estado reúne e estoca. Naturalmente, não se deve pensar que todos os dados abertos sejam informações sobre o comportamento de agentes públicos e destinados a promover um olhar heterônomo sobre quem toma decisões "em nome do povo". Os Estados em geral têm o maior número de instrumentos para produzir informações sobre praticamente tudo, de epidemias a taxas de juros, de inflação ao fluxo de transporte público, de número de nascimentos e óbitos a estatísticas eleitorais. Nem tudo é, tecnicamente, utilizável para transparência pública, mas tudo é dado público que pode servir aos cidadãos e às organizações para melhorar a vida de todos. 
Aparentemente, isso significa muito pouco, vez que as práticas e comportamentos humanos são principalmente analógicos, mas, em um mundo em acelerada digitalização e hiperconectado, em pouco tempo não fará mais sentido distinguir entre transparência off-line e eTransparência.

De qualquer forma, o objeto precípuo da atenção aqui consiste em entender como facilidades e instrumentos de comunicação em meios digitais, como projetos e iniciativas de natureza digital e como bancos de dados informatizados podem contribuir para produzir mais e melhor transparência em governos, instituições e organizações. 0 que já se pode antecipar, de forma sumária, sobre o estado da transparência digital?

1. A mais recente tendência em termos de transparência tem como foco ações baseadas na internet. Os princípios da Open Government Initiative, as mais recentes leis de acesso, diretrizes e normas de organismos multilaterais, novas leis relacionadas à transparência fiscal de governos e órgãos da administração pública, todas se apoiam fortemente na ideia de que a boa transparência deve implicar acesso irrestrito, o que significa em divulgação e disponibilidade de dados, relatórios, aplicativos de interface etc. em sites web e plataformas de comunicação digital. Neste sentido, a Lei de Responsabilidade Fiscal brasileira já responde à nova tendência de e-transparência.
2. Novos projetos e iniciativas que integram transparência e participação cidadã hoje se baseiam na internet. De orçamentos participativos digitais a projetos em que políticos, representantes eleitos e titulares da administração pública são compelidos a vir a público apresentar e discutir razões de Projetos de Lei ou de políticas públicas, antecipadamente ou a posteriori, as melhores novidades neste campo são iniciativas digitais.

3. Novos instrumentos e recursos para a produção de transparência são apoiados na mineração de dados (data mining) e nos aplicativos de monitoramento, raspagem de dados (data scraping) etc., que permitem que fontes heterônomas possam coletar e organizar informações mesmo sem cooperação interna dos sistemas monitorados. Estamos apenas no começo de uma era de ouro do monitoramento de agentes e agências públicas e de instituições e corporações públicas e privadas, a partir dos rastros digitais que hoje todos nós, inadvertidamente, deixamos para trás, seja para fins malignos (como a espionagem), seja para fins benignos, como a transparência produzida de forma heterônoma.

\section{Por outro lado}

Se é evidente, como parece a todos, que o princípio da publicidade e a sua materialização em regimes 
de transparência são definitivamente valores importantes na produção de governos baseados nos governados e de governos responsivos aos cidadãos, também neste caso há o outro lado, que precisa ser considerado.

Antes de tudo, o princípio da publicidade não é tão simples de justificar, como parece à primeira vista, vez que o segredo também pode se demonstrar um valor democrático - e pelas mesmas razões. Há razões utilitaristas (algumas práticas, que irão promover o maior bem ao maior número de pessoas, podem fracassar se não forem secretas), mas também há razões kantianas (privacidade, reserva, confidencialidade, que dependem de segredo, estão a fundamento da liberdade) ${ }^{5}$.

A questão, porém, é que, se o segredo e, até mesmo, a dissimulação podem se justificar em certos casos e acerca de certos objetos: a) a decisão secreta não pode ser uma falha moral e, sobretudo, não pode ser essa sua falha moral a razão pela qual ela precisa ser mantida em segredo para ser efetiva. Se a política tiver uma falha moral, o segredo ajuda a escondê-la para torná-la eficaz, mas a falha moral continua. 0 segredo republicanamente justificado não pode servir para isso; b) mesmo quando o segredo se faz necessário, não desaparece a obrigação de que em algum momento e para alguém diferente dos envolvidos a decisão tenha que ser justificada de maneira adequada, isto é, com razões públicas.

0s envolvidos na prática secreta devem, em algum momento, dar razões das práticas secretas, "respondendo às questões que desafiam tais razões e concordando em agir de acordo com os resultados dessas e de outras deliberações públicas" (GUTMANN; THOMPSON, 1996, p. 105).

Em segundo lugar, nem tudo são contentamentos no reino da transparência. Em princípio, a transparência deveria ter como resultado 0 incremento no nível de confiança dos que têm acesso às informações na instituição, organização ou governo transparente. A transparência é, afinal, um ato de coragem porque inicia de algum modo tornando vulnerável aquele que toma a decisão e a decisão por ele tomada. 0 controle e, portanto, o poder, passa, de algum modo, para o outro lado, para o lado de quem olha em vez do lado de quem age. Se 0 agente é transparente é porque assume a obrigação de ter que prestar contas e poder ser repreendido pelas decisões tomadas, logo, se garante. Mas nada é simples como parece ser, e a transparência pode se transformar numa crise de confiança no objeto da transparência.

A variável a se controlar aqui é o que a transparência nos permite capturar. Naturalmente, falamos aqui da transparência a posteriori, da revisão pública da decisão ou ação já praticadas. Governo, instituições e 
organizações transparentes só continuarão a ser consideradas confiáveis se 0 que a transparência revelar for uma contínua e tranquilizadora percepção de comportamentos impecáveis ou, no mínimo, objeto de pequenas falhas. Se, ao contrário, a transparência, principalmente quando não é oferecida pelos agentes e instituições, mas arrancada à custa de investigação ou vazamentos, trouxer-nos informações sobre condutas escandalosas e práticas chocantemente inapropriadas, a confiança no governo, instituição ou organização é substituída imediatamente por desconfiança, suspeita e rejeição.

Não é que as pessoas deixem de gostar da transparência, o que não gostam é daquilo que a transparência lhes permite divisar em certos casos. Neste caso, a instituição perderá a confiança e 0 apreço geral, sendo ela transparente ou não. 0 que significa que a transparência não protege governos, instituições e organizações da desconfiança e do desapreço público; ao contrário, podem aumentar exponencialmente 0 risco de ambos quando as decisões e os comportamentos aí adotados forem considerados incompatíveis com o interesse público. Eis por que não há vantagens na transparência para sistemas políticos ou políticas organizacionais apoiadas em patrimonialismo, clientelismo e fisiologismo. Por outro lado, a crise de confiança nas instituições transparentes pode se estender para uma crise de confiança no governo ou na própria democracia, o que pode levar governos a se fecharem ainda mais. De qualquer forma, há necessidade de estudos mais aprofundados para entender a fase de "crise de confiança" na passagem de regimes patrimonialistas e governos opacos para regimes responsivos e governos abertos. 0 Brasil é, certamente, um laboratório a céu aberto.

\section{Referências}

ALMADA, M. P. Avaliação da eTransparência em Portais de Governos Nacionais: Uma Comparação entre Brasil, Estados Unidos e Reino Unido. Tese (Doutorado em Comunicação Social) - Programa de Pós-Graduação em Comunicação e Cultura Contemporâneas, Universidade Federal da Bahia, 2017.

\section{AMORIM, P. K. Democracia e Internet: a}

transparência de gestão nos portais eletrônicos das capitais brasileiras. Tese (Doutorado em Comunicação Social) - Programa de Pós-Graduação em Comunicação e Cultura Contemporâneas, Universidade Federal da Bahia, Salvador, 2012.

BASTIDA, F; BENITO, B. Central government budget practices and transparency: An international comparison. Public Administration, v. 85, n. 3, p. 667-716, 2007. DOI: 10.1111/j.1467-9299.2007.00664.x

BENTHAM, J. Of Publicity. Chap 2 of Essay on Political Tactics. In The Works of Jeremy Bentham. Edinburgh: William Tait, 1839.

BOHMAN, J. Public Deliberation: Pluralism, Complexity and Democracy. Cambridge: The MIT Press, 1996.

. Citizenship and Norms of Publicity:

Wide Public Reason in Cosmopolitan Societies. Political Theory, v. 27, n. 2, p. 176-202, 1999. doi:10.1177/0090591799027002002

BRASIL. Lei complementar $\mathrm{n}^{0} 101$, de 4 de maio de 2000. Brasília: Presidência da República. Disponível em: < http:///www.planalto.gov.br/ccivil/leis/LCP/ Lcp101.htm>. Acesso em: 1 fev. 2015. 
Lei complementar 131, de 27 de maio de 2009. "Lei da Transparência". Disponível em: http:// www.planalto.gov.br/ccivil_03/leis/LCP/Lcp131.htm. Acesso em 26 de julho de 2016.

Decreto 7.724, de 16 de maio de 2012. "Regulamenta a Lei nr. 12.525/2011". Disponível em: http://www.planalto.gov.br/ccivil_03/_ato20112014/2012/decreto/d7724.htm. Acesso em 15 de novembro de 2017.

Lei $\mathrm{n}^{0} \mathbf{1 2 . 5 2 7}$, de 18 de novembro de 2011. Brasília: Presidência da República. Disponível em: < http://www.planalto.gov.br/ccivil_03/_ato20112014/2011/lei/l12527.htm > . Acesso em: 18 fev. 2015.

Decreto No 8.777 de 11 de maio de 2016. Brasília, 2016. Disponível em: < http://www.planalto. gov.br/ccivil_03/_Ato2015-2018/2016/Decreto/D8777. htm >. Acesso em: 29 ago. 2016.

FINEL, B. I.; LORD, K. M. The Surprising Logic of Transparency. International Studies Quarterly, v. 3, n. 2, p. 315-339, 1999. doi:10.2307/2600758.

\section{GUTMANN, A.; THOMPSON, D. Democracy and} disagreement. Cambridge: Harvard University Press, 1996.

HABERMAS, J. Faktizität und geltung. Frankfurt a. M.: Suhrkamp Frankfurt, 1992.

HARRISON, T. M., et al. Open government and e-government: Democratic challenges from a public value perspective. Information Polity, v. 17, n. 2, p. 83-97, 2012. doi:10.3233/IP-2012-0269

HEALD, D. Varieties of Transparency. In: HOOD, C.; HEALD, D. (org). Transparency: the key to better governance? Nova York: Oxford University Press, p. 25-43, 2006.

KANT, I. Schrift zum ewigen Frieden. In W. Weischedel (Ed.), Werkausgabe v. 12, Frankfurt a. M.: Suhrkamp Verlag, p. 191-259, 1795.

LINDERS, D.; WILSON, S. C. What is open government?: one year after the directive.
In 12th Annual International Conference on Digital Government Research, p. 262-271, 2011. doi:10.1145/2037556.2037599

LUNA-REYES, L. F.; BERTOT, J. C.; MELLOULI, S. Open Government, Open Data and Digital Government. Government Information Quarterly, v. 31, n. 1, p. 4-5, 2014doi:10.1016/j.giq.2013.09.001

MARGETTS, H. Transparency and digital government. In: HOOD, C.; HEALD, D. (org). Transparency: the key to better governance? Nova York: Oxford University Press, p. 197-210, 2006.

\section{MEIJER, A. Understanding modern transparency.}

International Review of Administrative Sciences, v. 75, n. 2, p. 255-269, 19 jun 2009.

\section{MCDERMOTT, P. Building open government.}

Government Information Quarterly, v. 27, n. 4, p. 401-413, 2010. doi:10.1016/j.giq.2010.07.002

MEIJER, A. J.; CURTIN, D.; HILLEBRANDT, M. Open government: connecting vision and voice. International Review of Administrative Sciences, v. 78, n. 1, p. 10-29, 2012. doi:10.1177/0020852311429533

MESKELL, D. Transparency and Open Government. GSA Office of Citizen Services and Communications, 2009. Disponível em: http://www.astrid.eu/Malamminis/ Documenti/GSA_Transparency_000.pdf(nhttp://www. au.af.mil/au/awc/awcgate/gsa/transparency_000.pdf

MITCHELL, R. B. Sources of Transparency: Information Systems in International Regimes. International Studies Quarterly, v. 42, n. 1, p. 109-130, 1998. doi:10.1111/0020-8833.00071

NAGEL, T. Concealment and Exposure. Philosophy \& Public Affairs, v. 27, n. 1, p. 3-30, jan. 1998.

RAWLS, J. A Theory of Justice. Cambridge: Harvard University Press, 1971.

SAMPAIO, R. C. Orçamentos Participativos Digitais: um mapeamento mundial das experiências já realizadas e suas contribuições para e-participação 
e e-democracia. Tese (Doutorado em Comunicação

Social) - Programa de Pós-Graduação em Comunicação

e Cultura Contemporâneas, Universidade Federal da

Bahia, Salvador, 2014.

SHADBOLT, N., et al. Linked open government data:

Lessons from data.gov.uk. IEEE Intelligent Systems, v. 27, n. 3, p.16-24, 2012. doi:10.1109/MIS.2012.23.

UNITED STATES. Open government directive.

Washington, DC: The White House, 2009. Presidential

Document. Memorandum for the Heads of Executive

Departments and Agencies. Disponível em: < https://

obamawhitehouse.archives.gov/open/documents/open-

government-directive >. Acesso em: 20 abril 2017. 


\begin{tabular}{|c|c|}
\hline $\begin{array}{l}\text { New challenges for the } \\
\text { idea of transparency }\end{array}$ & $\begin{array}{l}\text { Nuevos desafíos para la idea } \\
\text { de transparencia pública }\end{array}$ \\
\hline $\begin{array}{l}\text { Abstract } \\
\text { The research in transparency has been refreshed } \\
\text { object of study in many different academic areas. } \\
\text { The public debate on transparency, although, } \\
\text { becomes complicated by a set of concepts and other } \\
\text { entries (such as publicity and accountability) that } \\
\text { compete with it, overlap it, gain new connotations } \\
\text { and emphases. This theoretical work aims: to order } \\
\text { the plurality of terms and concepts through which } \\
\text { the public transparency is referred in the literature; } \\
\text { to define and detail public transparency and its } \\
\text { dynamics in the practices and conduct of governments } \\
\text { and institutions; to suggest the place of resources and } \\
\text { environments of digital communication in the future of } \\
\text { the debate on public transparency. } \\
\text { Keywords } \\
\text { Democracy. Public Transparency. Publicity. }\end{array}$ & $\begin{array}{l}\text { Resumen } \\
\text { La investigación en transparencia ha sido } \\
\text { revigorizado objeto de estudio de las más diversas } \\
\text { áreas académicas. El debate público sobre } \\
\text { transparencia se ve complicado por un conjunto } \\
\text { de otros conceptos y verdades (como publicidad } \\
\text { y accountability) que con él concurren, a él se } \\
\text { superponen, ganan nuevos énfasis. Este trabajo de } \\
\text { cuño teórico tiene el objetivo de ordenar la pluralidad } \\
\text { de términos y conceptos mediante los cuales la } \\
\text { transparencia pública es referida en la literatura } \\
\text { especializada; definir y detallar la transparencia } \\
\text { pública y sus dinámicas en las prácticas y conductas } \\
\text { de gobiernos e instituciones; sugerir el lugar de los } \\
\text { recursos y ambientes de la comunicación digital en el } \\
\text { futuro del debate sobre transparencia pública. } \\
\text { Palabras-clave }\end{array}$ \\
\hline
\end{tabular}




\section{Expediente}

A revista E-Compós é a publicação científica em formato eletrônico da Associação Nacional dos Programas de Pós-Graduação em Comunicação (Compós). Lançada em 2004, tem como principal finalidade difundir a produção acadêmica de pesquisadores da área de Comunicação, inseridos em instituições do Brasil e do exterior.

\section{E-COMPÓS I www.e-compos.org.br I E-ISSN 1808-2599}

Revista da Associação Nacional dos Programas de Pós-Graduação em Comunicação. Brasília, v.21, n.2, maio/ago. 2018. A identificação das edições, a partir de 2008, passa a ser volume anual com três números. Indexada por Latindex I www.latindex.unam.mx

\section{CONSELHO EDITORIAL}

Ada Cristina Machado Silveira, Universidade Federal de Santa Maria, Brasil Alda Cristina Silva da Costa, Universidade Federal do Pará, Brasil Alfredo Luiz Paes de Oliveira Suppia, Universidade Estadual de Campinas, Brasil Ana Regina Barros Rego Leal, Universidade Federal do Piauí, Brasil Ana Carolina Rocha Pessôa Temer, Universidade Federal de Goiás, Brasil André Luiz Martins Lemos, Universidade Federal da Bahia, Brasil Angela Cristina Salgueiro Marques, Universidade Federal de Minas Gerais, Brasil Ângela Freire Prysthon, Universidade Federal de Pernambuco, Brasil Anna Cristina Pertierra, Western Sidney University - Australia Antonio Carlos Hohlfeldt, Pontifícia Universidade Católica do Rio Grande do Sul, Brasil Arthur Ituassu, Pontifícia Universidade Católica do Rio de Janeiro, Brasil Bruno Campanella, Universidade Federal Fluminense, Brasil Bushra Rahman, University of the Punjab, Paquistão Cláudio Novaes Pinto Coelho, Faculdade Cásper Líbero, Brasil Cárlida Emerim, Universidade Federal de Santa Catarina, Brasil Carlos Del Valle Rojas, Universidad de La Frontera, Chile Carlos Eduardo Franciscato, Universidade Federal de Sergipe, Brasil Danilo Rothberg, Universidade Estadual Paulista, Brasil Denise Tavares da Silva, Universidade Federal Fluminense, Brasil Diógenes Lycarião, Universidade Federal do Ceará, Brasil Doris Martines Vizcarrondo, Universidad de Porto Rico, Porto Rico Eduardo Vicente, Universidade de São Paulo, Brasil Eliza Bachega Casadei, Escola Superior de Propaganda e Marketing - SP, Brasil Elvira Gomes dos Reis, Universidade do Cabo Verde, Cabo Verde Eneus Trindade, Universidade de São Paulo, Brasil Erick Felinto de Oliveira, Universidade do Estado do Rio de Janeiro, Brasil Erick Torrico, Universidad Andina Simón Bolívar, Bolívia Erly Vieira Júnior, Universidade Federal do Espírito Santo, Brasil Fabio La Rocca, Université Paul Valéry Montpellier III, França Fernando Firmino da Silva, Universidade Federal da Paraíba, Brasil Francisco de Assis, FIAM-FAAM Centro Universitário, Brasil Francisco Elinaldo Teixeira, Universidade Estadual de Campinas, Brasil Francisco Gilson R. Pôrto Jr., Universidade Federal do Tocantins, Brasil Francisco Sierra Caballero, Ciespal, Equador

Frederico de Mello Brandão Tavares, Universidade Federal de Ouro Preto, Brasil Gabriela Reinaldo, Universidade Federal do Ceará, Brasi Gérman Rey, Pontifícia Universidad Javeriana, Colômbia Gilson Vieira Monteiro, Universidade Federal do Amazonas, Brasil Gustavo Daudt Fischer, Universidade do Vale do Rio dos Sinos, Brasil Gustavo Hernández Díaz, Universidad Central de Venezuela, Venezuela Heidi Figueroa Sarriera, Universidad de Puerto Rico, Porto Rico Ignacio Aguaded, Universidad Huelva, Espanha

Inesita Soares de Araújo, FIOCRUZ, Brasil Itania Maria Mota Gomes, Universidade Federal da Bahia, Brasil Jiani Adriana Bonin, Universidade do Vale do Rio dos Sinos, Brasil João Carlos Correia, Universidade de Beira Interior, Portugal Jonathan Cohen, da University of Haifa, Israel José Afonso da Silva Junior, Universidade Federal de Pernambuco, Brasil José Luiz Aidar Prado, Pontifícia Universidade Católica de São Paulo, Brasil Josette Maria Monzani, Universidade Federal de São Carlos, Brasil Juçara Gorski Brittes, Universidade Federal de Ouro Preto, Brasil Julián Durazo Herrmann, Université du Québec à Montréal Juliana Freire Gutmann, Universidade Federal da Bahia, Brasil
Karla Covarrubias, Universidad de Colima, México Laura Loguercio Cánepa, Universidade Anhembi Morumbi, Brasil Leonel Azevedo de Aguiar, Pontifícia Universidade Católica do Rio de Janeiro, Brasi Letícia Cantarela Matheus, Universidade do Estado do Rio de Janeiro, Brasil Ling Chen, Hong Kong Baptist University Luciana Coutinho Souza, Universidade de Sorocaba, Brasil Maria Ataide Malcher, Universidade Federal do Pará, Brasil Maria Elena Hernández Ramírez, Universidad de Guadalajara, México Maria Elisabete Antonioli, Escola Superior de Propaganda e Marketing - SP, Brasil Maria das Graças Pinto Coelho, Universidade Federal do Rio Grande do Norte, Brasil Maria Teresa Quiroz, Universidad de Lima, Peru Marialva Carlos Barbosa, Universidade Federal do Rio de Janeiro, Brasil Marina Poggi, Universidad Nacional de Quilmes, Argentina Marcel Vieira Barreto Silva, Universidade Federal da Paraíba, Brasil Marcia Tondato, Escola Superior de Propaganda e Marketing, Brasil Marli Santos, Universidade Metodista de São Paulo, Brasil Márcio Souza Gonçalves, Universidade do Estado do Rio de Janeiro, Brasil Mateus Yuri Passos, Universidade Metodista de São Paulo, Brasil Mauricio Mario Monteiro, Universidade Anhembi Morumbi, Brasil Mayka Castellano, Universidade Federal Fluminense, Brasil Mirna Varela, Universidad de Buenos Aires, Argentina Mozahir Salomão Bruck, Pontifícia Universidade Católica de Minas Gerais, Brasil Neyla Pardo, Universidad Nacional de Colombia, Colombia Nísia Martins Rosario, Universidade Federal do Rio Grande do Sul, Brasil Olga Guedes Bailey, Nottingham Trent University, Inglaterra Paolo Demuru, Universidade Paulista, Brasil Paolo Peverini, L.O.U.I.S.S de Roma, Itália

Paško Bilić, Institute for Development and International Relations, Croácia Paula Melani Rocha, Universidade Estadual de Ponta Grossa, Brasil Potiguara Mendes Silveira Jr, Universidade Federal de Juiz de Fora, Brasil Priscila Ferreira Perazzo, Universidade Municipal de São Caetano do Sul, Brasil Rafael Cardoso Sampaio, Universidade Federal do Paraná, Brasil Rafael Tassi Teixeira, Universidade Tuiuti do Paraná, Brasil Regiane Lucas Garcês, Universidade Federal de Minas Gerais, Brasil Regiane Regina Ribeiro, Universidade Federal do Paraná, Brasil Renata Pitombo Cidreira, Universidade Federal do Recôncavo da Bahia, Brasil Renato Essenfelder, Escola Superior de Propaganda e Marketing, Brasil Roberto Elísio dos Santos, Universidade Municipal de São Caetano do Sul, Brasil Robson Borges Dias, Universidade Católica de Brasília (UCB), Brasil Rodolfo Rorato Londero, Universidade Estadual de Londrina, Brasil Rosario Sánchez Vilela, Universidad Católica del Uruguay, Uruguai Roseli Figaro, Universidade de São Paulo, Brasil

Saima Saeed, Jamia Millia Islamia, India Sara Brandelero, Leyden University, Holanda

Simone Maria Andrade Pereira de Sá, Universidade Federal Fluminense, Brasil Sônia Caldas Pessoa, Universidade Federal de Minas Gerais, Brasil Sun Sun Lim, Singapore University of Technology and Design, Singapura Tatiana Oliveira Siciliano, Pontifícia Universidade Católica do Rio de Janeiro, Brasil Thaïs de Mendonça Jorge, Universidade de Brasília, Brasil Valquiria Michela John, Universidade Federal do Paraná, Brasil Vicki Mayer, Tulane University, Estados Unidos Yamile Haber Guerra, Universidad de Oriente, Cuba 


\section{CONSELHO CIENTÍFICO}

Cristiane Freitas Gutfreind, Pontifícia Universidade Católica do Rio Grande do Sul, Brasil I Eduardo Antônio de Jesus, Universidade Federal de Minhas Gerais, Brasil | Eduardo Morettin, Universidade de São Paulo, Brasil I Irene de Araújo Machado, Universidade de São Paulo, Brasil | Miriam de Souza Rossini, Universidade Federal do Rio Grande do Sul, Brasil

\section{COMISSÃO EDITORIAL}

Igor Pinto Sacramento, Universidade Federal do Rio de Janeiro, Brasil । Kelly Cristina de Souza Prudencio, Universidade Federal do Paraná, Brasil । Osmar Gonçalves dos Reis Filho, Universidade Federal do Ceará, Brasil | Rafael Grohmann, Faculdade Cásper Líbero, Brasil | Thaiane Moreira de Oliveira, Universidade Federal Fluminense, Brasil (editores associados)

\section{CONSULTORES AD HOC}

Alessandro Constantino Gamo, Universidade Federal de São Carlos (UFSCAR) | Amanda Mauricio Pereira Leite, Universidade Federal do Tocantins (UFT) | Amílcar Almeida Bezerra, Universidade Federal de Pernambuco (UFPE) I Ana Carolina Damboriarena Escosteguy, Universidade Federal de Santa Maria (UFSM) I Ana Luiza Coiro Moraes, Faculdade Cásper Líbero | Antonio Pacca Fatorelli, Universidade Federal do Rio de Janeiro (UFRJ) | Ariane Diniz Holzbach, Universidade Federal Fluminense (UFF) I Benjamin Picado, Universidade Federal Fluminense (UFF) I César Augusto Baio dos Santos, Universidade Federal do Ceará (UFC) I César Geraldo Guimarães, Universidade Federal de MInas Gerais (UFMG) I César Ricardo Siqueira Bolaño, Universidade de Brasília (UNB) I Ciro Marcondes Filho, Universidade de São Paulo (USP) I Felipe Simão Pontes, Universidade Estadual de Ponta Grossa I Felipe Trotta, Universidade Federal Fluminense (UFF) I Gislene da Silva, Universidade Federal de Santa Catarina (UFSC) I Kati Caetano, Universidade Tuiuti do Paraná I Laan Mendes de Barros, Universidade Estadual Paulista Júlio de Mesquita Filho I Lucia Leão, Pontifícia Universidade Católica de São Paulo (PUC-SP) I Jairo Getulio Ferreira, Universidade do Vale do Rio dos Sinos (UNISINOS) | Juliana Doretto, FIAM-FAAM | Juliano Maurício de Carvalho, Universidade Estadual Paulistaa Júlio de Mesquita Filho | Lilian Cristina Monteiro França, Universidade Federal de Sergipe I Liziane Soares Guazina, Universidade de Brasília (UNB) I Luís Mauro Sá Martino, Faculdade Cásper Líbero | Luiz Peres Neto, Escola Superior de Propaganda e Marketing (ESPM) I Herom Vargas, Universidade Metodista de São Paulo I Inês Silvia Vitorino Sampaio, Universidade Federal do Ceará (UFC) I Maria Helena Weber, Universidade Federal do Rio Grande do Sul (UFRGS) I Mariana Baltar, Universidade Federal Fluminense (UFF) I Maurício de Bragança, Universidade Federal Fluminense (UFF) I Mauro de Souza Ventura- Universidade Estadual Paulista Júlio de Mesquita Filho I Muniz Sodre de Araujo Cabral, Universidade Federal do Rio de Janeiro (UFRJ) I Nuno Manna, Universidade Federal da Bahia (UFBA) I Rosana de Lima Soares, Universidade de São Paulo (USP) I Sandra Maria Lúcia Pereira Gonçalves, Universidade Federal do Rio Grande do Sul (UFRGS) I Sérgio Luiz Gadini, Universidade Estadual de Ponta Grossa I Talitha Gomes Ferraz, Escola Superior de Propaganda e Marketing (ESPM) I Victa de Carvalho Pereira da Silva, Universidade Federal do Rio de Janeiro (UFRJ)

\section{EQUIPE TÉCNICA}

ASSISTENTES EDITORIAL Melina Santos | REVISÃO DE TEXTOS Fátima Áli | EDITORAÇ̃̃o ELETRÔNICA Roka Estúdio

COMPÓS I www.compos.org.br

Associação Nacional dos Programas de Pós-Graduação em Comunicação

Presidente

Marco Roxo

Programa de Pós-Graduação em Comunicação - UFF marcos-roxo@uol.com.br

Vice-Presidente

Isaltina Gomes

Programa de Pós-Graduação em Comunicação - UFPE

isaltina@gmail.com

Secretária-Geral

Gisela Castro

Programa de Pós-Graduação em Comunicação

e Práticas de Consumo - ESPM

castro.gisela@gmail.com

CONTATO I revistaecompos@gmail.com 